Article

\title{
How the Urban Neighborhood Environment Influences the Quality of Life of Chinese Community-Dwelling Older Adults: An Influence Model of "NE-QoL"
}

\author{
Fan Zhang ${ }^{1(1)}$ and Dezhi $\mathrm{Li}^{1,2, *}$ \\ 1 Department of Construction and Real Estate, School of Civil Engineering, Southeast University, \\ Nanjing, Jiangsu 211189, China; 230159075@seu.edu.cn \\ 2 Engineering Research Center of Building Equipment, Energy and Environment, Southeast University, \\ Nanjing, Jiangsu 211189, China \\ * Correspondence: njldz@seu.edu.cn; Tel.: +86-1377-032-2938
}

Received: 22 August 2019; Accepted: 14 October 2019; Published: 17 October 2019

\begin{abstract}
Due to functional impairment and low mobility, the sphere of activities of older adults often shrinks and they rely on their living environment more. Especially for urban community-dwelling older adults who are aging in place, the urban neighborhood environment affects their quality of life (QoL) heavily. This study aims to explore how the urban neighborhood environment affects QoL of community-dwelling older adults and develop a mediation model called "Neighborhood Environment-Quality of Life (NE-QoL)" for community-dwelling older adults. The reliability test is applied to test and modify the questionnaire based on cross-sectional data collected from the survey, the multiple regression analysis is used to identify significant influence relations between variables of neighborhood environment and dimensions of the QoL, mediation effects are assumed and tested by the mediation analysis in SPSS, and then the "NE-QoL" is developed to reveal the detailed influence path between the urban neighborhood environment and QoL of community-dwelling older adults. The "NE-QoL" model reveals seven variables of the urban neighborhood environment, which influences the QoL of community-dwelling older adults significantly, and three mediation effects exist in the influence path, making clear the understanding about the relationship between neighborhood environment and the QoL of community-dwelling older adults. It provides valuable retrofit guidelines of the neighborhood environment for improving QoL of community-dwelling older adults.
\end{abstract}

Keywords: Urban neighborhood environment; quality of life; community-dwelling older adults; mediation effects

\section{Introduction}

The aging population keeps increasing worldwide, especially in China. According to the World Population Ageing Report 2015 [1], until 2050, the worldwide population of older adults over 60 will increase to 2 billion, accounting for a proportion of $21.5 \%$, while Chinese older adults will reach 0.5 billion, which is $36.5 \%$ of all populations in China. Facing with this aging issue, how can we help this huge number of older adults age successfully?

Traditionally, older adults usually choose to age in professional care facilities, like nursing institutions, or age at home by receiving help from family members. However, both two ways have several limitations. Professional nursing institutions can provide high-quality services to older adults, but the expense is pretty high, and only a minority of older adults can afford it. In the meantime, 
almost older all adults do not want to move to an unfamiliar environment like nursing institutions [2]. Differently, older adults who choose to age at home need not pay for professional services, so the majority of older adults prefer aging at home. Previously older adults can get enough support from family members, but as the repaid development of the country, people are busier at work and less time at home, therefore more older adults cannot get enough support from family recent years [3].

Besides two ways mentioned above, "aging in place" is a new concept that encourages and support older people to live within their familiar neighborhood environment at home rather than to move to special care facilities. "Aging in place" emphasizes older people stay in their familiar living environment rather than move to specific care facilities [4,5]. According to a survey of People's Daily Online, around $90 \%$ of Chinese older adults prefer aging in place. This part of older adults aging in place are called "community-dwelling older adults". The main limitation to support successful aging of community-dwelling older adults is high requirements on their original living environment, since most of their time are spent within neighborhood and indoor environment due to their functional impairment and low mobility [6-8]. Consequently, it is quite essential to conduct living environment improvement for enhancing the quality of life $(\mathrm{QoL})$ of community-dwelling older adults.

Generally, people can be seen as nested within and moving around their living environment at different spatial scales, like region-scale, city-scale, or community-scale $[7,8]$. According to the multi-scale environment geographical framework (as shown in Figure 1) [8], the micro-level living environment refers to indoor environment of home/households, the macro-level living environment means the environment of the whole city, region or country, and then the neighborhood environment belongs to the meso-level living environment. Due to the functional impairment and competence decline of older adults, areas of their movement and activity shrink significantly, not much beyond several blocks nearby [9]. That is to say, most of community-dwelling older adults' time is spent within meso-level and micro-level living environment, so the neighborhood environment is pretty important to community-dwelling older adults.

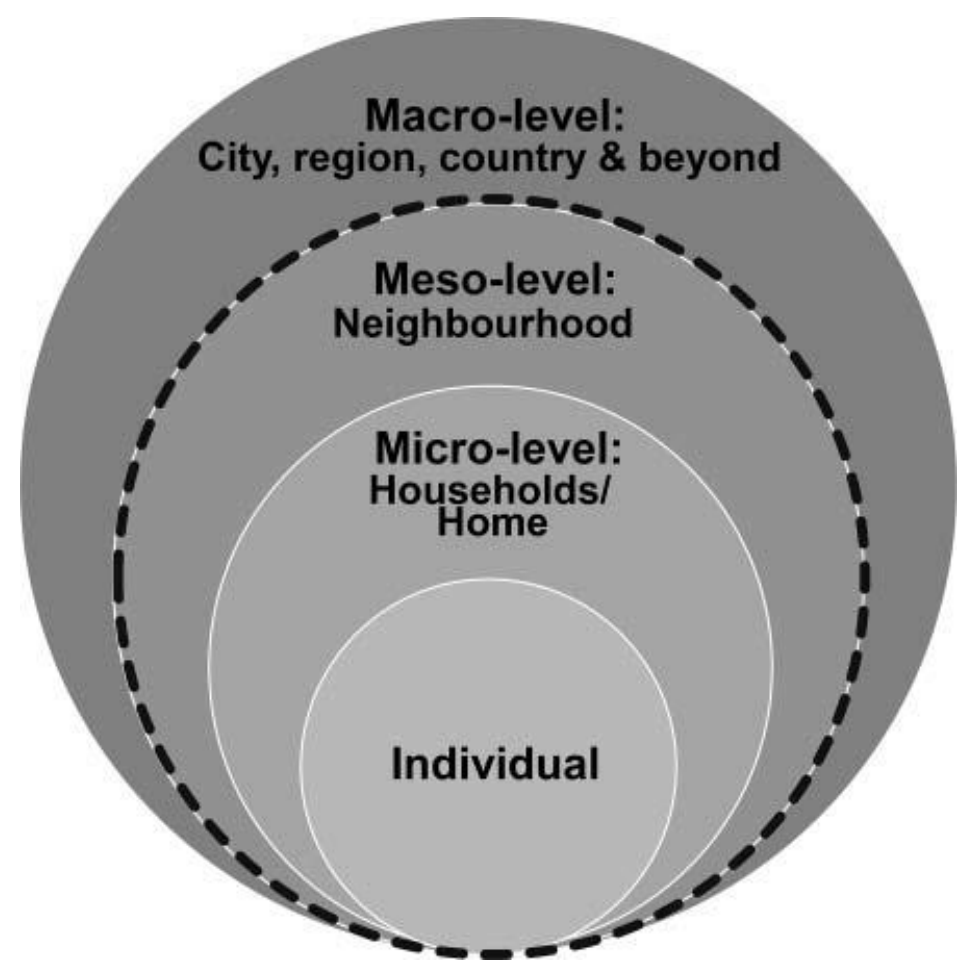

Figure 1. The multi-scale environment geographical framework. Source: [8].

QoL is adopted as the criterion to judge whether community-dwelling older adults can age successfully in their communities. QoL does not have an exact definition until now. Many experts from 
different research fields have raised several definitions of QoL according to their researches. The concept of QoL is proposed in the medical field at the very beginning, so the initial QoL mainly refers to health-related QoL, focusing on individual physical and psychogenic health [10]. Then researchers considered some other factors which are less related to medical can also affect QoL, such as income, freedom and satisfaction. Nowadays, QoL has developed into a systematic research field. The one of the most popular definition of QoL is proposed by the World Health Organization Quality of Life (WHOQOL) Group as individuals' perception of their position in life in the context of the culture and value system in which they live and in relation to their goals, expectation, standards and concerns [11]. In terms of WHOQOL-BREF, an abbreviated version of the WHOQOL-100 quality of life assessment developed by WHOQOL Group, physical health, psychological health, social relationship and living environment are four main dimensions of QoL [11,12].

Since the neighborhood environment plays a quite important role in older adults' life, many researchers have already conducted studies related to the neighborhood environment and older adults. Many researchers use quantitative and qualitative methods to explore the neighborhood environmental factors which have a significant impact on older adults in several aspects like wellbeing, residential satisfaction, and physical activities. The street connectivity and social cohesion [13], security facilities, communal facilities, activities center for aged people, and convenience of shopping and medical service [14] influence capability wellbeing of community-dwelling older adults; outdoor space, care facilities, medical facilities, barrier-free facilities, community services, service accessibility [15], environmental problem [16] influence elderly life satisfaction; and environmental accessibility [17], parks [18], safety, comfort of movement [9], peer support [9,18] and proportion of residents living in extreme poverty [19] are found to affect physical activities of older adults in their daily life heavily. Furthermore, "Person-Environment Fit" (P-E Fit) was proposed by Lawton in the field of gerontology [20,21]. "P-E Fit" reveals the less competent individuals, like the elderly, are more likely to be affected by the environment, and it were applied in many recent researches exploring the relation between environment and older adults [15,22,23].

Besides, there is significant research focusing on the neighborhood environment of older adults and their QoL, like overall QoL, health-related QoL and social life. Neighborhood safety, social cohesion [24], social support [25], barrier-free design [26], security, control, accessibility, condition of sidewalks and placement of crosswalk [27] are neighborhood environmental factors which are closely associated with overall QoL of older adults. The safety from traffic, walking level, safe parks, street noise level [28], aesthetics, physical barriers and crime [29] impact on health-related QoL of older adults, while the distance to the nearest green space or senior center are regarded as non-significant factors to health-related QoL of older adults [30]. The percent poverty, residential stability, concentration of elders influence the self-rated health of older adults [31], but other researcher considered the built environment of a neighborhood to have a weak association with self-rated health of older adults [32]. In aspects of mental health, the depressive symptoms of older adults can be affected by neighborhood support networks and perceived proximity by walk to facilities [33], and the slower rated of cognitive decline of older adults can be caused by community resources, proximity to public transit and public spaces in good condition [34]. Furthermore, neighborhood walkability is an important issue affecting older adults' social life [35].

Based on the review above, it is obvious that different factors of neighborhood environment may have different influence relations with older adults. The composition and inner relationship of the neighborhood environment are quite complex, usually consisting of physical environment, natural environment, social environment, facilities within neighborhood environment and safety [36]. Seldom researches consider the whole neighborhood environment as a comprehensive system that contains all possible influence factors of older adults, and explore the complex influence relationship between neighborhood environment and QoL of community-dwelling older adults.

However, there is a lack of specific analysis, which considers parts of the neighborhood environment as mediators in the influence model of urban neighborhood environment and QoL for supporting 
aging of community-dwelling older adults. Consequently, this study focuses on complex influence paths between urban neighborhood environment and QoL of community-dwelling older adults, and aims to identify significant neighborhood environmental factors affecting QoL of community-dwelling older adults, check if any mediation effects exist in influence paths, and then develop the influence model of community-dwelling older adults called "NE-QoL (Neighborhood Environment-Quality of Life)". Based on data collected with the questionnaire survey, the reliability test, multiple regression and the mediation effect test are conducted to establish "NE-QoL" model of community-dwelling older adults, providing evidence to improve neighborhood environment for supporting aging efficiently.

\section{Materials and Methods}

\subsection{Conceptual Model}

According to the literature review and theory of "Person-Environment Fit" [15,37], neighborhood environment can affect the QoL of community-dwelling older adults directly. Besides, based on the complex inner relationship of neighborhood environment [36], these variables which have significant direct effects may play different roles in influencing relations. Part of variables of the neighborhood environment are regarded as mediators, which can be also affected by other variables, and the other part of variables of neighborhood environment are regarded as independent variables which can affect mediators. Thus, the conceptual model of this study is proposed as shown in Figure 2. Both independent variables and mediator of neighborhood environment have direct effects on the QoL of community-dwelling older adults which is regarded as dependent variables, and independent variables also have mediation effects on dependent variables through mediators. This conceptual model (Figure 2) is proposed to illustrate complex influence paths between neighborhood environment and QoL of community-dwelling older adults.

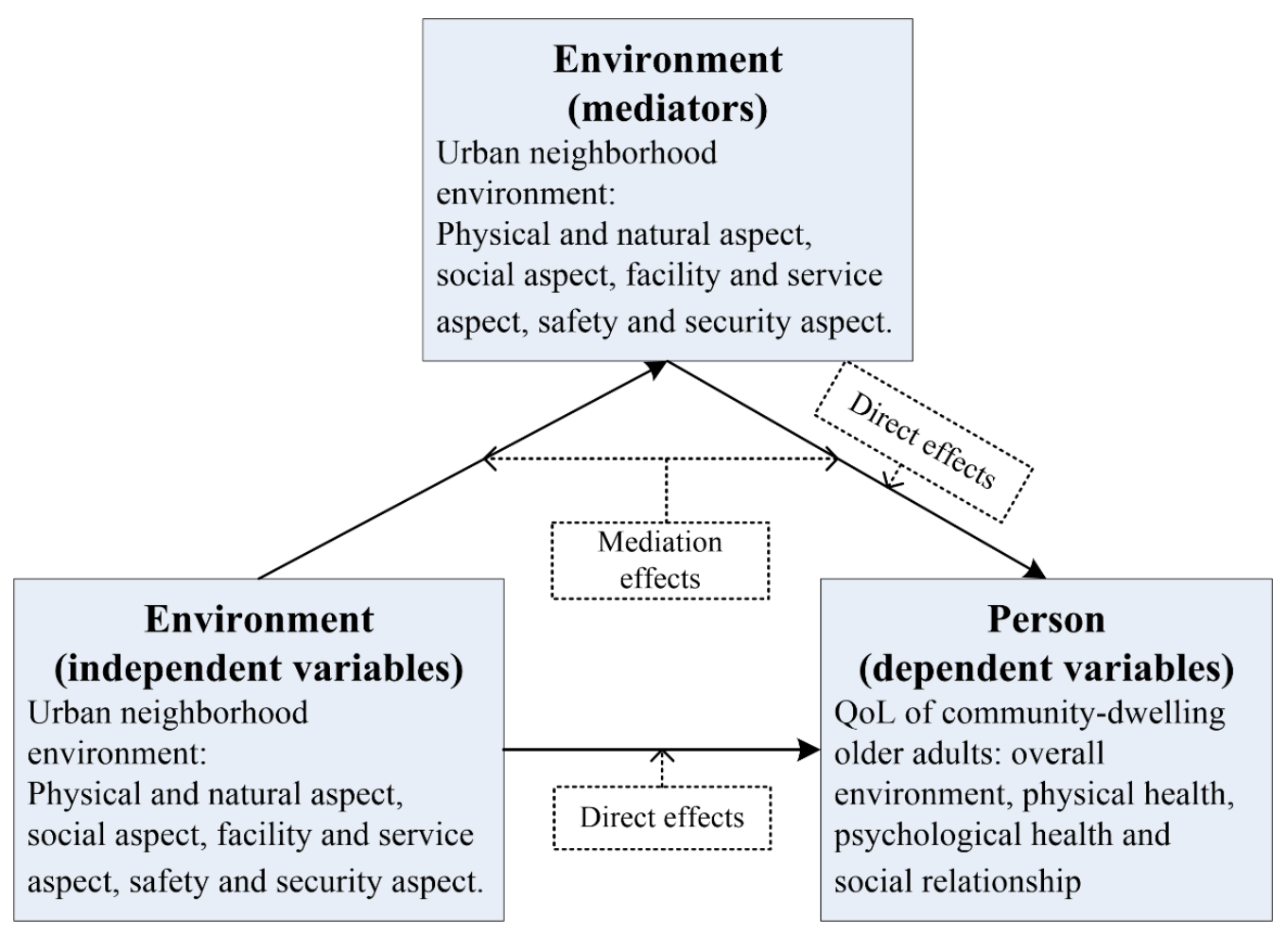

Figure 2. The conceptual model of urban neighborhood environment and quality of life (QoL) of community-dwelling older adults. 


\subsection{Questionnaire Design}

Based on the literature review and previous studies [36,38], the questionnaire is designed to identify the significant variables of neighborhood environment affecting QoL of community-dwelling older adults, hypnotize and test mediation effects between them. The questionnaire contains three main parts: general information of respondents, neighborhood environment and QoL assessments.

Part 1: General information of respondents

All respondents are community-dwelling older adults. The general information of respondents in the questionnaire include their age, gender, type of community, who they live with, length of residence.

Part 2: Neighborhood environment assessment

The next part of the questionnaire is an assessment of neighborhood environment. There were 16 main neighborhood environmental factors belonging to physical and natural aspects; social aspect, facility and service aspect and safety and security aspect were identified by our systematic literature review about urban neighborhood environmental factors affecting the QoL of older adults [36]. In this study, these 16 neighborhood environmental factors are adopted as variables of the urban neighborhood environment, including physical and natural aspect: (E1) land-use mix, (E2) barrier-free design, (E3) street condition, (E4) sidewalk condition, (E5) natural environment; social aspect: (E6) neighbor support; facility and service aspect: (E7) public transport, (E8) outdoor public spaces, (E9) facilities related to health \& security, (E10) facilities related to physical exercise \& recreation, (E11) facilities related to daily life, (E12) accessibility to facilities; safety and security aspects: (E13) traffic-related safety, (E14) crime-related safety, (E15) design-related safety and (E16) security [36].

Since these variables cannot be measured directly, each variable is assessed by measurable items in detail. Through interviews with 30 community-dwelling older adults, measurable items are summarized by grounded theory, and then determined by 5 experts from university, government and real estate company. All variables of the neighborhood environment and its measurable items are listed in Table 1. For instance, the variable of 'sidewalk condition' is measured by three measurable items the surface evenness of sidewalk, the width of sidewalk, and the sidewalk for the blind. 44 measurable items belong to 16 variables of the neighborhood environment in total. Respondents are asked to describe their satisfaction with each measurable item of neighborhood environment, and the 5-point Likert scale is applied to quantize the satisfaction level, ranging from 1 (very unsatisfied) to 5 (very satisfied). The final score of variables is the average value of its measurable items.

Table 1. Variables and measurable items of the neighborhood environment.

\begin{tabular}{ccc}
\hline Variable & Code & Measurable Item \\
\hline \multirow{2}{*}{ E1 Land-use mix } & 1 & Types of the functional area \\
& 2 & Scales of the functional area \\
E2 Barrier-free design & 3 & Degree of mixing of functional area \\
& 5 & Barrier-free design at the entrance of the residential building \\
& 6 & Barrier-free design in public space \\
E3 Street condition & 7 & Barrier-free design in community facilities \\
& 9 & Street network \\
& 10 & Crowdedness of streets \\
E4 Sidewalk condition & 11 & Height of curbs \\
& 12 & Street noise \\
& 13 & Surface evenness of sidewalk road \\
E5 Natural environment & 15 & Width of sidewalk road \\
& 16 & Sidewalk for the blind \\
& & Air quality outdoors \\
& & Greening rate of the neighborhood \\
& & Comfort level outdoors on rainy or snowy days \\
\hline
\end{tabular}


Table 1. Cont.

\begin{tabular}{|c|c|c|}
\hline Variable & Code & Measurable Item \\
\hline \multirow{3}{*}{ E6 Neighbor support } & 17 & Number of neighbors \\
\hline & 18 & Familiarity with neighbors \\
\hline & 19 & Support or helps from neighbors \\
\hline \multirow{3}{*}{ E7 Public transport } & 20 & Bus stations for the neighborhood \\
\hline & 21 & Subway stations for the neighborhood \\
\hline & 22 & Parks within the neighborhood \\
\hline \multirow[t]{2}{*}{ E8 Outdoor public spaces } & 23 & Entertainment squares within the neighborhood \\
\hline & 24 & Long corridors within the neighborhood \\
\hline \multirow[t]{2}{*}{$\begin{array}{l}\text { E9 Facilities related to } \\
\text { health \& security }\end{array}$} & 25 & $\begin{array}{l}\text { Facilities related to the health of older adults within the neighborhood } \\
\text { (e.g., clinics, pharmacies, community health centers, rehabilitation } \\
\text { centers, etc.) }\end{array}$ \\
\hline & 26 & $\begin{array}{c}\text { Facilities related to the security of older adults within the } \\
\text { neighborhood (e.g., monitoring facilities, guards, entrance control } \\
\text { system, etc.) }\end{array}$ \\
\hline \multirow{2}{*}{$\begin{array}{l}\text { E10 Facilities related to } \\
\text { physical exercise \& } \\
\text { recreation }\end{array}$} & 27 & $\begin{array}{l}\text { Facilities related to physical exercises of older adults within the } \\
\text { neighborhood (e.g., senior centers, fitness equipment, swimming } \\
\text { pools, etc.) }\end{array}$ \\
\hline & 28 & $\begin{array}{l}\text { Facilities related to recreations of older adults within the } \\
\text { neighborhood (e.g., community libraries, senior centers, etc.) }\end{array}$ \\
\hline \multirow{3}{*}{$\begin{array}{l}\text { E11 Facilities related to } \\
\text { daily life }\end{array}$} & 29 & $\begin{array}{c}\text { Shopping facilities within the neighborhood (e.g., supermarkets, } \\
\text { shopping malls, grocery stores, etc.) }\end{array}$ \\
\hline & 30 & $\begin{array}{l}\text { Specific facilities within the neighborhood (e.g., newsstands, banks, } \\
\text { bookstore, laundries, etc.) }\end{array}$ \\
\hline & 31 & $\begin{array}{l}\text { Other facilities related to daily life within the neighborhood (e.g., } \\
\text { parking lot, delivery lockers, drinking water facilities, etc.) }\end{array}$ \\
\hline \multirow{4}{*}{$\begin{array}{l}\text { E12 Accessibility to } \\
\text { facilities }\end{array}$} & 32 & Travel distance to facilities \\
\hline & 33 & Travel time to facilities \\
\hline & 34 & Roads connecting to facilities \\
\hline & 35 & Safety of motor vehicles \\
\hline \multirow[t]{2}{*}{ E13 Traffic-related safety } & 36 & Safety of non-motor vehicles \\
\hline & 37 & Safety of pedestrians \\
\hline \multirow{3}{*}{ E14 Crime-related safety } & 38 & Personal safety outdoors in the daytime \\
\hline & 39 & Personal safety outdoors at night \\
\hline & 40 & Safety of design related to streets \\
\hline \multirow[t]{2}{*}{ E15 Design-related safety } & 41 & Safety of design related to different levels \\
\hline & 42 & Safety of design related to outdoor public spaces \\
\hline \multirow{2}{*}{ E16 Security } & 43 & Security from neighborhood design and planning \\
\hline & 44 & Security from security facilities \\
\hline
\end{tabular}

\section{Part 3: QoL assessment}

The third part of the questionnaire assesses the QoL of community-dwelling older adults. Based on the WHOQOL-BREF proposed by WHOQOL Group in 1996 [11,12], QoL of community-dwelling older adults is assessed by four dimensions: $(\mathrm{Q} 1)$ overall $\mathrm{QoL},(\mathrm{Q} 2)$ physical health, $(\mathrm{Q} 3)$ psychological health and (Q4) social relationship, using 17 measurable items to describe four dimensions of QoL of older adults (as shown in Table 2). For example, the social relationship of older adults is measured by two items-'How satisfied are you with your personal relationships?' and 'How satisfied are you with the support you get from your friends?'. All the items are scored based on the steps of WHOQOL-BREF [12]. 
Table 2. Variables and measurable items of the quality of life (QoL) of community-dwelling older adults.

\begin{tabular}{ccc}
\hline Dimension & Code & Measurable Item \\
\hline Q1 Overall QoL & 1 & How would you rate your quality of life? \\
& 2 & How would you feel about your personal wellbeing? \\
Q2 Physical health & 3 & To what extent do you feel that physical pain prevents you \\
from doing what you need to do?
\end{tabular}

\subsection{Sampling and Data Collection}

This survey aims to obtain data about the neighborhood environment that community-dwelling older adults perceive and their QoL. Since this study focuses on community-dwelling older adults, the sampling criteria are set as older adults who are over 60 and who live in communities instead of professional care institutions. Only older adults meet criteria can be sampled as respondents of this questionnaire.

Based on the questionnaire, two rounds of surveys were conducted during October 2018 in the urban area of Nanjing, China. The initial questionnaire is designed according to measurable items of neighborhood environment and QoL assessment. The first-round data collection and feedback from 30 community-dwelling older adults for pilot study by interviewing them with the initial questionnaire. According to the feedback, descriptions of measurable items were revised for a clearer expression. Then the second-round survey is conducted by random sampling. When the whole population is huge and the sampling proportion is less than 0.05 , the whole population can be regarded as the infinite population. Therefore, older adults in the urban area of Nanjing, which are around 0.682 million, is regarded as the infinite population. According to the rule of simple random sampling, the sample size of the infinite population should more than 173 under a 5\% sampling error. 204 eligible respondents who are sampled randomly from communities in the urban area of Nanjing are participated through completing the revised questionnaire and 192 valid questionnaires are collected. The response rate of this survey reaches to $94.12 \%$. The general information of respondents is listed in Table $3.65 .10 \%$ of older adults are sixty to seventy, $15.10 \%$ are seventy to eighty, and the other $19.80 \%$ are over eighty years old. $48.96 \%$ of respondents are female, and $51.04 \%$ are male. 
Table 3. General information of respondents.

\begin{tabular}{cccc}
\hline General Information of Respondents & Options & Frequency & Percentage \\
\hline \multirow{3}{*}{ Age } & $60-69$ & 125 & $65.10 \%$ \\
& $70-79$ & 29 & $15.10 \%$ \\
Gender & $\geq 80$ & 38 & $19.80 \%$ \\
& Female & 94 & $48.96 \%$ \\
& Male & 98 & $51.04 \%$ \\
Type of community & Commercial housing & 116 & $60.42 \%$ \\
& Affordable housing & 8 & $4.17 \%$ \\
& Self-built housing & 55 & $28.64 \%$ \\
& Others & 13 & $6.77 \%$ \\
Who they live with & Live alone & 16 & $8.33 \%$ \\
& Live with partner & 119 & $61.98 \%$ \\
& Live with children & 49 & $25.52 \%$ \\
& Others & 8 & $4.17 \%$ \\
Length of residence & $\leq 5$ years & 47 & $24.48 \%$ \\
& 5-10 years & 46 & $23.96 \%$ \\
& $\geq 10$ years & 99 & $51.56 \%$ \\
\hline
\end{tabular}

\subsection{Data Analysis}

At the beginning of the analysis, a reliable test is necessary to check the reliability of the questionnaire. The Cronbach's alpha value ( $\alpha$-value) is chosen to show the reliability, only when the $\alpha$-value is over 0.6 or when $\alpha$-value if deleted is under original $\alpha$-value, measurable items in the questionnaire can be accepted, otherwise the item should be excluded [39]. Since the part of QoL assessment in the questionnaire is developed and validated by WHO [12], the validation test is also essential to be applied to identify the validation of part of the neighborhood environment assessment. Only when the Kaiser-Meyer-Olkin (KMO) value is higher than 0.6, Bartlett's test is significant, and factor loading of measurable items are more than 0.4 , measurable items of neighborhood environment assessment can be accepted [40].

The multiple regression analysis is used to identify all variables of neighborhood environment which can affect dimensions of QoL significantly. The value of the variable of neighborhood environment is set as the average of its measurable values. The multiple regression analysis is conducted in the Statistical Package of Social Science (SPSS) version 22.0 (IBM, Armonk, NY, United States, 2013).

According to the conceptual model (Figure 2), only when direct effects between variable of neighborhood environment and dimension of QoL is significant, the existence of mediation effect between them can be possible. Our previous study has already analyzed and concluded the inner relationship among neighborhood environment affecting QoL of older adults qualitatively [36]. So, based on the inner relationship and results of the multiple regression analysis, hypotheses of mediation effects are proposed, including simple mediation effects and multiple mediation effects. Then the mediation effect test is applied to verify if any mediation effects exist in the significant influence. The mediation effect test is conducted in PROCESS Procedure for SPSS v2.16 provided by Dr. Hayes [41]. Generally, the mediation effect test usually contains three tests: the multiple stepwise regression, Sobel test and Bootstrap test. Since researchers have pointed out that Sobel test has limitations in the test of simple mediation effects [42,43], and these limitations are more obvious in the test of multiple mediation effects [44]. Thus, Sobel test is only conducted in the simple mediation effects, but do not used in the multiple mediation effects. Only when the hypothesis of simple mediation effects is supported by the multiple stepwise regression, Sobel test and Bootstrap test, the hypothesis of multiple mediation effects is supported by the multiple stepwise regression and Bootstrap test, the hypothesis is valid.

Finally, the "NE-QoL" model of community-dwelling older adults is developed based on results of the multiple regression and the mediation effect test. The whole flow path of the methodology of this study is as shown in Figure 3. 


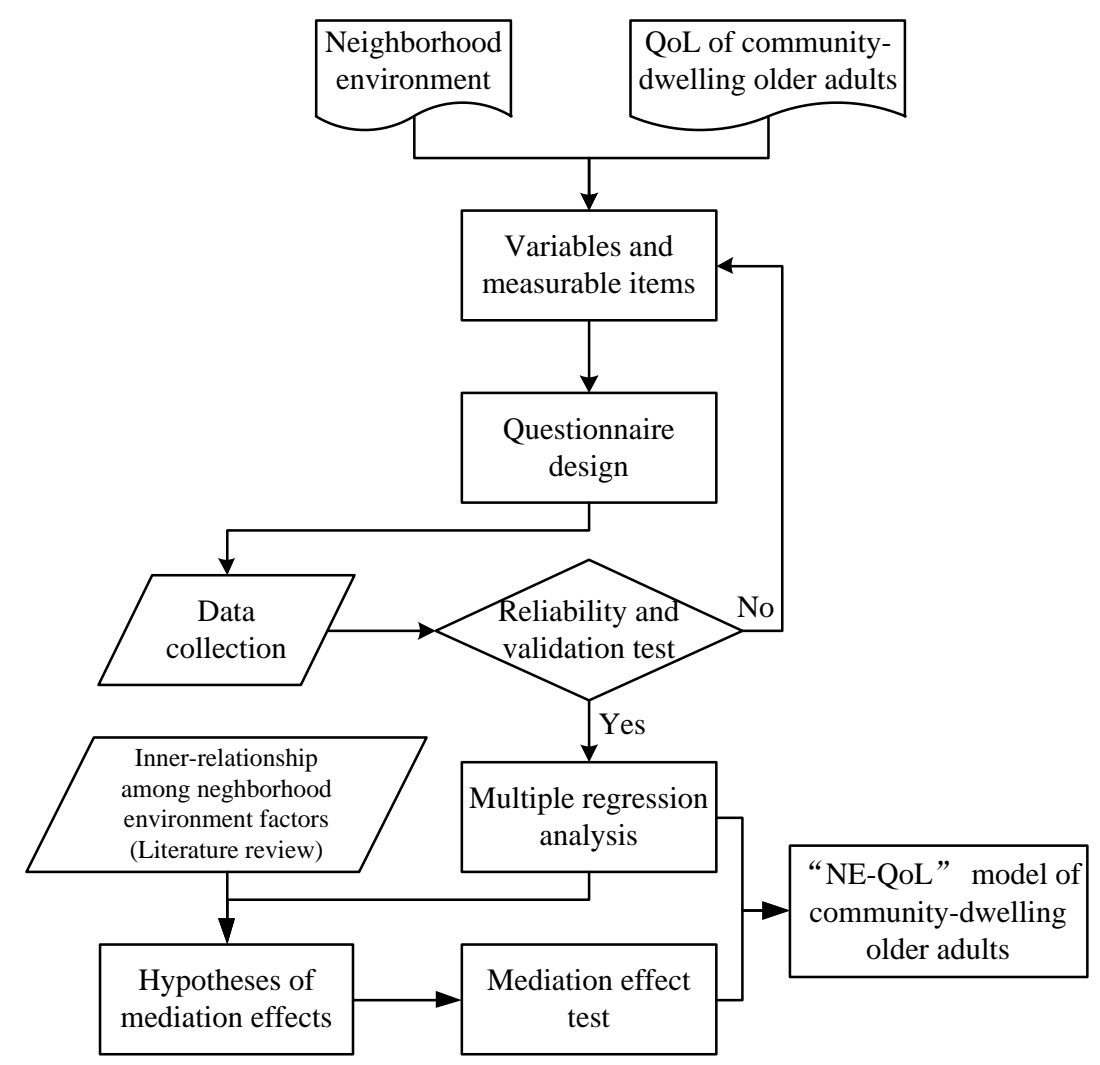

Figure 3. The research flow chart of the methodology.

\section{Results}

\subsection{Reliability and Validation Test of the Questionnaire}

The reliability test is applied to examine the internal consistency of both neighborhood environment and QoL measurements. Table 4; Table 5 present results of the reliability test of the neighborhood environment and QoL of older adults separately. The $\alpha$-value is the indicator to show the result of the reliability test. Generally speaking, if $\alpha$-value is greater than 0.6 , the detail items in the questionnaire are acceptable; if $\alpha$-value is greater than 0.7 , the detail items in the questionnaire are pretty appropriate; if $\alpha$-value is less than 0.6 , that means the questionnaire needs to be modified $[39,45]$. Besides, " $\alpha$-value if deleted" is another important indicator which means the final $\alpha$-value if this item is deleted from the original list. If " $\alpha$-value if deleted" is much higher than original $\alpha$-value, it indicates this item has negative effects on the reliability, and this item should be removed from the measurable items.

Regarding Table 4 , all the $\alpha$-value of variables of the neighborhood environment are greater than 0.8 , indicating that all detail items are suitable for this study. According to the $\alpha$-value if deleted, the $\alpha$-value will decrease or cannot increase significantly no matter which measurable item is deleted from the questionnaire, which means measurable items of neighborhood environment don't need to be modified. Then, Table 5 shows results of reliability test of QoL measurements. Results show the internal consistency of QoL measurement is not good, especially the dimension of physical health and psychological health. The physical health is assessed by 7 items, and its initial $\alpha$-value is only 0.458 , less than 0.6. " $\alpha$-value if deleted" of item 3 and item 4 are much higher than 0.458 , so if item 3 and item 4 can be deleted, the $\alpha$-value of physical health will increase significantly. After both item 3 and 4 are removed, the $\alpha$-value of physical health increase to 0.817 . Besides, even though the $\alpha$-value of psychological health meets the requirement of reliability test, deleting item 15 can heavily improve the $\alpha$-value to 0.853 . Thus, item 15 is also removed from QoL measurements. 
Table 4. The reliability and validation test of the neighborhood environment.

\begin{tabular}{|c|c|c|c|c|c|c|}
\hline Variable & $\begin{array}{c}\text { Code of } \\
\text { Measurable } \\
\text { Item }\end{array}$ & $\begin{array}{l}\text { Factor } \\
\text { Loading }\end{array}$ & $\alpha$-Value & $\begin{array}{c}\alpha \text {-Value If } \\
\text { Deleted }\end{array}$ & $\begin{array}{c}\text { Final } \\
\alpha \text {-Value }\end{array}$ & Decision \\
\hline \multirow{3}{*}{ E1 Land-use mix } & 1 & 0.772 & \multirow{3}{*}{0.931} & 0.946 & \multirow{3}{*}{0.931} & Accept \\
\hline & 2 & 0.865 & & 0.883 & & Accept \\
\hline & 3 & 0.878 & & 0.867 & & Accept \\
\hline \multirow{3}{*}{ E2 Barrier-free design } & 4 & 0.863 & \multirow{3}{*}{0.944} & 0.924 & \multirow{3}{*}{0.944} & Accept \\
\hline & 5 & 0.816 & & 0.899 & & Accept \\
\hline & 6 & 0.752 & & 0.930 & & Accept \\
\hline \multirow{4}{*}{ E3 Street condition } & 7 & 0.571 & \multirow{4}{*}{0.930} & 0.909 & \multirow{4}{*}{0.930} & Accept \\
\hline & 8 & 0.693 & & 0.914 & & Accept \\
\hline & 9 & 0.735 & & 0.901 & & Accept \\
\hline & 10 & 0.749 & & 0.910 & & Accept \\
\hline \multirow{4}{*}{ E4 Sidewalk condition } & 11 & 0.595 & \multirow{4}{*}{0.844} & 0.830 & \multirow{4}{*}{0.844} & Accept \\
\hline & 12 & 0.646 & & 0.710 & & Accept \\
\hline & 13 & 0.810 & & 0.797 & & Accept \\
\hline & 14 & 0.707 & & 0.836 & & Accept \\
\hline \multirow[t]{3}{*}{ E5 Natural environment } & 15 & 0.642 & \multirow[t]{3}{*}{0.883} & 0.802 & \multirow[t]{3}{*}{0.883} & Accept \\
\hline & 16 & 0.490 & & 0.866 & & Accept \\
\hline & 17 & 0.767 & & 0.911 & & Accept \\
\hline \multirow[t]{2}{*}{ E6 Neighbor support } & 18 & 0.815 & \multirow[t]{2}{*}{0.895} & 0.827 & \multirow[t]{2}{*}{0.895} & Accept \\
\hline & 19 & 0.845 & & 0.792 & & Accept \\
\hline \multirow{3}{*}{ E7 Public transport } & 20 & 0.645 & \multirow{3}{*}{0.815} & - & \multirow{3}{*}{0.815} & Accept \\
\hline & 21 & 0.751 & & - & & Accept \\
\hline & 22 & 0.437 & & 0.917 & & Accept \\
\hline \multirow[t]{2}{*}{ E8 Outdoor public spaces } & 23 & 0.528 & \multirow[t]{2}{*}{0.916} & 0.852 & 0.917 & Accept \\
\hline & 24 & 0.569 & & 0.864 & & Accept \\
\hline E9 Facilities related to & 25 & 0.607 & & - & & Accept \\
\hline health \& security & 26 & 0.539 & 0.844 & - & 0.844 & Accept \\
\hline E10 Facilities related to & 27 & 0.792 & & - & & Accept \\
\hline physical exercise \& & 28 & 0.823 & 0.947 & - & 0.947 & Accept \\
\hline $\begin{array}{l}\text { recreation } \\
\text { F11 Facilities related to }\end{array}$ & 29 & 0.591 & & 0.730 & & Accept \\
\hline E11 Facilities related to & 30 & 0.421 & 0.874 & 0.858 & 0.874 & Accept \\
\hline & 31 & 0.846 & & 0.873 & & Accept \\
\hline & 32 & 0.578 & & 0.938 & & Accept \\
\hline E12 Accessibility to & 33 & 0.588 & 0.962 & 0.928 & 0.962 & Accept \\
\hline & 34 & 0.620 & & 0.962 & & Accept \\
\hline & 35 & 0.540 & & 0.943 & & Accept \\
\hline E13 Traffic-related safety & 36 & 0.657 & 0.926 & 0.860 & 0.926 & Accept \\
\hline & 37 & 0.578 & & 0.875 & & Accept \\
\hline & 38 & 0.696 & & - & & Accept \\
\hline E14 Crime-related satety & 39 & 0.625 & 0.910 & - & 0.910 & Accept \\
\hline & 40 & 0.461 & & 0.957 & & Accept \\
\hline E15 Design-related safety & 41 & 0.473 & 0.942 & 0.910 & 0.942 & Accept \\
\hline & 42 & 0.419 & & 0.877 & & Accept \\
\hline F16 Security & 43 & 0.787 & & - & & Accept \\
\hline Elo security & 44 & 0.715 & 0.925 & - & 0.925 & Accept \\
\hline
\end{tabular}


Table 5. The reliability test of the QoL of community-dwelling older adults.

\begin{tabular}{|c|c|c|c|c|c|}
\hline Dimension & $\begin{array}{c}\text { Code of Measurable } \\
\text { Item }\end{array}$ & $\alpha$-Value & $\begin{array}{c}\alpha \text {-Values If } \\
\text { Deleted }\end{array}$ & $\begin{array}{c}\text { Final } \\
\alpha \text {-Value }\end{array}$ & Decision \\
\hline \multirow{2}{*}{ Q1 Overall QoL } & 1 & \multirow[t]{2}{*}{0.922} & - & \multirow[t]{5}{*}{0.922} & Accept \\
\hline & 2 & & - & & Accept \\
\hline \multirow{7}{*}{ Q2 Physical health } & 3 & \multirow[t]{7}{*}{0.456} & 0.642 & & Remove \\
\hline & 4 & & 0.597 & & Remove \\
\hline & 5 & & 0.331 & & Accept \\
\hline & 6 & & 0.304 & \multirow[t]{6}{*}{0.853} & Accept \\
\hline & 7 & & 0.291 & & Accept \\
\hline & 8 & & 0.249 & & Accept \\
\hline & 9 & & 0.287 & & Accept \\
\hline \multirow{6}{*}{ Q3 Psychological health } & 10 & \multirow[t]{6}{*}{0.713} & 0.589 & & Accept \\
\hline & 11 & & 0.573 & & Accept \\
\hline & 12 & & 0.638 & \multirow{4}{*}{0.853} & Accept \\
\hline & 13 & & 0.631 & & Accept \\
\hline & 14 & & 0.635 & & Accept \\
\hline & 15 & & 0.853 & & Remove \\
\hline \multirow{2}{*}{ Q4 Social relationship } & 16 & \multirow[t]{2}{*}{0.835} & - & \multirow[t]{2}{*}{0.835} & Accept \\
\hline & 17 & & - & & Accept \\
\hline
\end{tabular}

The QoL assessment was already validated by WHO and previous studies. So, in order to validate the neighborhood environment assessment, 44 measurable items of neighborhood environment are factor analyzed by varimax rotation. The KMO value is 0.939 , higher than 0.6 , and the significance of Bartlett's test is 0.000, which means it satisfies the factor analysis [40]. Then, the varimax rotation is conducted in the SPSS, and factor loadings of 44 measurable items of 16 variables are listed in Table 4 . All factor loadings exceed 0.4, indicating that all measurable items are qualified to be accepted in the questionnaire.

\subsection{Results of Multiple Regression Analysis}

After revising the measurable items based on the reliability test, the weighted average of scores of its measurable items is calculated as the final score of each variable of neighborhood environment and each dimension of the QoL of community-dwelling older adults. According to the conceptual model (Figure 2), all variables of the neighborhood environment are possible to influence the QoL of community-dwelling older adults. Therefore, the multiple regression analysis is conducted to explore the significant influence of neighborhood environment on QoL of community-dwelling older adults, and stepwise regression is chosen to be the variable selection method. Results of multiple regression analysis are shown in Table 6.

It reveals that each dimension of QoL is significantly influenced by at least one variable of the neighborhood environment. The neighbor support (E6), accessibility to facilities (E12) and facilities related to physical exercise \& recreation (E10) influence the overall QoL, explaining $46.2 \%$ of the variance of the overall QoL of community-dwelling older adults; the neighbor support (E6) influences physical health significantly, explaining $10.5 \%$ of the variance of the physical health of community-dwelling older adults; the facilities related daily life (E11), neighbor support (E6), sidewalk condition (E4) and natural environment (E5) influence have significant influence on psychological health, explaining $26.3 \%$ of the variance of the psychological health of community-dwelling older adults; and the neighbor support (E6), accessibility to facilities (E11) and design-related safety (E15) are main influence of social relationship of community-dwelling older adults, explain $29.7 \%$ of the variance of the social relationship of community-dwelling older adults. 
Table 6. Results of the multiple regression analysis.

\begin{tabular}{|c|c|c|c|c|c|c|c|c|c|}
\hline \multirow{2}{*}{ Model } & & \multirow{2}{*}{ B $(95 \%$ CI $)$} & \multirow{2}{*}{ S.E. } & \multirow{2}{*}{$\mathbf{t}$} & \multirow{2}{*}{ Sig. } & \multirow{2}{*}{$\mathbf{R}$} & \multirow{2}{*}{$\mathbf{R}^{2}$} & \multicolumn{2}{|c|}{ ANOVA } \\
\hline & & & & & & & & F & Sig. \\
\hline \multirow{4}{*}{ Q1 Overall QoL } & Constant & $\begin{array}{c}1.032 \\
(0.622-1.441)\end{array}$ & 0.208 & 4.970 & 0.000 & 0.679 & 0.462 & 53.743 & 0.000 \\
\hline & E6 & $\begin{array}{c}0.384 \\
(0.240-0.529)\end{array}$ & 0.073 & 5.244 & 0.000 & & & & \\
\hline & E12 & $\begin{array}{c}0.226 \\
(0.083-0.369)\end{array}$ & 0.072 & 3.125 & 0.002 & & & & \\
\hline & E10 & $\begin{array}{c}0.123 \\
(0.007-0.240)\end{array}$ & 0.060 & 2.085 & 0.038 & & & & \\
\hline \multirow[t]{3}{*}{ Q2 Physical health } & Constant & $\begin{array}{c}2.454 \\
(1.996-2.911)\end{array}$ & 0.232 & 10.581 & 0.000 & 0.324 & 0.105 & 22.538 & 0.000 \\
\hline & E6 & $\begin{array}{c}0.301 \\
(0.176-0.427)\end{array}$ & 0.064 & 4.728 & 0.000 & & & & \\
\hline & Constant & $\begin{array}{c}0.394 \\
(-0.539-1.326)\end{array}$ & 0.473 & 0.833 & 0.406 & 0.512 & 0.263 & 16.640 & 0.000 \\
\hline \multirow[t]{5}{*}{$\begin{array}{l}\text { Q3 Psychological } \\
\text { health }\end{array}$} & E11 & $\begin{array}{c}0.324 \\
(0.195-0.452)\end{array}$ & 0.065 & 4.959 & 0.000 & & & & \\
\hline & E6 & $\begin{array}{c}0.151 \\
(0.003-0.299)\end{array}$ & 0.075 & 2.009 & 0.046 & & & & \\
\hline & $\mathrm{E} 4$ & $\begin{array}{c}0.254 \\
(0.107-0.401)\end{array}$ & 0.075 & 3.410 & 0.001 & & & & \\
\hline & E5 & $\begin{array}{c}0.187 \\
(0.032-0.342)\end{array}$ & 0.078 & 2.386 & 0.018 & & & & \\
\hline & Constant & $\begin{array}{c}0.444 \\
(-0.604-1.491)\end{array}$ & 0.531 & 0.836 & 0404 & 0.545 & 0.297 & 26.450 & 0.000 \\
\hline \multirow{3}{*}{$\begin{array}{l}\text { Q4 Social } \\
\text { relationship }\end{array}$} & E6 & $\begin{array}{c}0.466 \\
(0.317-0.614)\end{array}$ & 0.075 & 6.183 & 0.000 & & & & \\
\hline & E11 & $\begin{array}{c}0.268 \\
(0.120-0.416)\end{array}$ & 0.075 & 3.577 & 0.000 & & & & \\
\hline & E15 & $\begin{array}{c}0.205 \\
(0.034-0.377)\end{array}$ & 0.087 & 2.359 & 0.019 & & & & \\
\hline
\end{tabular}

Notes: $\mathrm{B}=$ unstandardized beta; S.E. = standard error; Sig. = significance.

\subsection{Hypotheses of Mediation Effects}

Results of multiple regression analysis show that several variables of neighborhood environment influence different dimensions of QoL of older adults directly and significantly. Since only when the influence between two variables is significant, the mediation effect is possible to exist in this influence path. The inner relationship among these 16 variables of the neighborhood environment has been proved qualitatively in the previous study (as shown in Figure 4) [36]. The variables in different levels play various roles in the whole neighborhood environment. In Figure 4, the variables located in the higher level (level 1\&2) influenced by other variables more, variables located in the lower level (level $4 \& 5$ ) influence other variables more, while variables located in the middle level (level 3) are the linkage between higher levels and lower levels. Therefore, possible mediation effects can be developed based on this inner relationship and results of multiple regression analysis. Ultimately, four hypotheses of mediation effects are proposed as follows. 


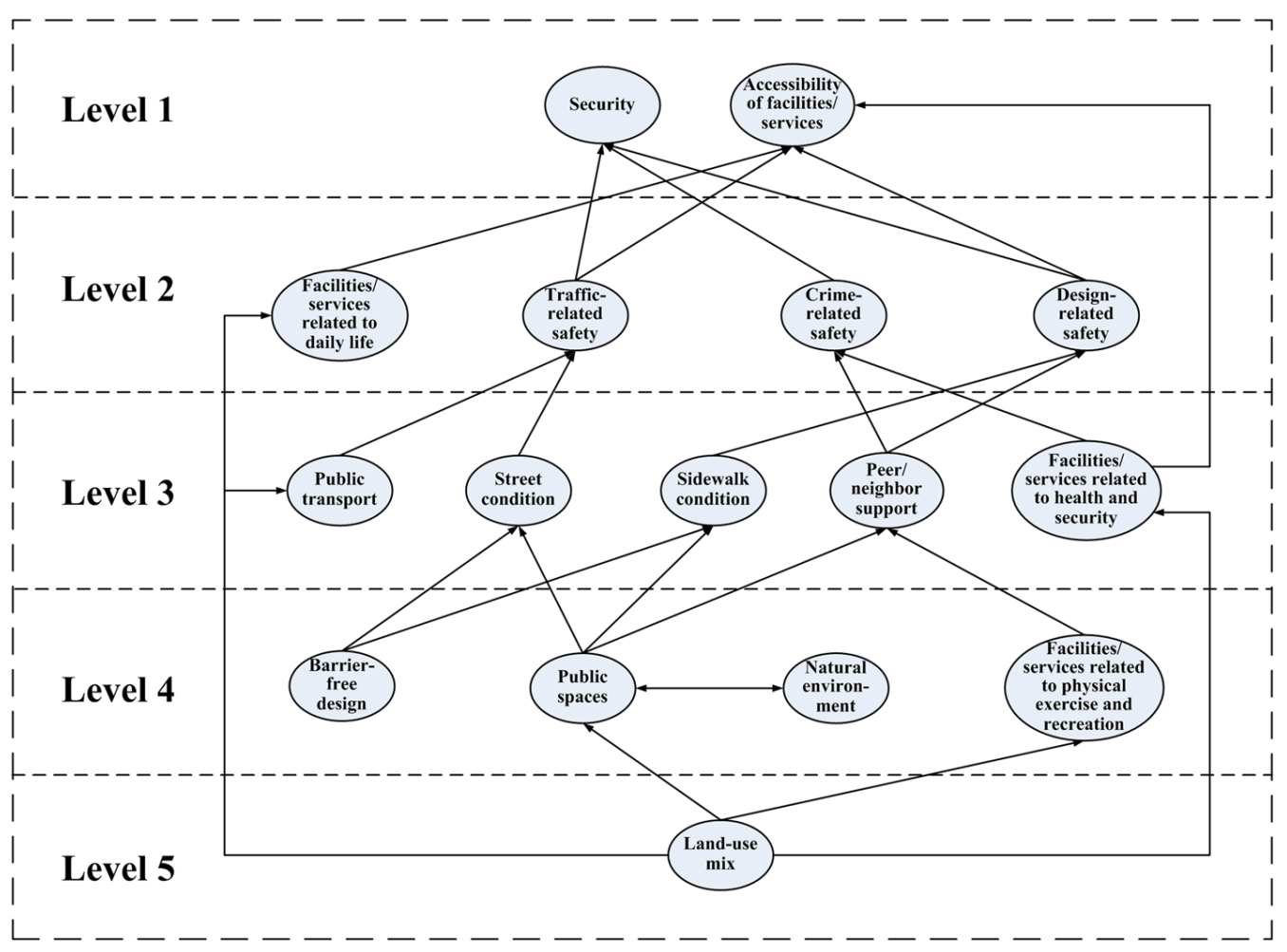

Figure 4. The inner relationship among variables of neighborhood environment. Source: [36].

Hypothesis 1: Facilities related to physical exercise $\mathcal{E}$ recreation $\rightarrow$ neighbor support $\rightarrow$ accessibility to facilities $\rightarrow$ overall QoL.

The first hypothesis is related to the dimension of overall QoL (Q1). As shown in Table 6, the neighbor support (E6), accessibility to facilities (E12) and facilities related to physical exercise \& recreation (E10) are three variables of neighborhood environment influencing the overall QoL of community-dwelling older adults heavily. Figure 4 shows that accessibility to facilities (E12) is in the level 1 of the inner relationship among all variables, neighbor support (E6) is in the level 3, while facilities related to physical exercise \& recreation (E10) is in the level 4. Facilities related to physical exercise \& recreation (E10) are always decided by planning and design of communities rather than other neighborhood environmental variables, and the planning and design of facilities can affect other variables more. While the accessibility to facilities (E12) always depends on other variables, including locations of facilities, distance to facilities, or scales of facilities [46,47].In addition, the neighbor support (E6) can be the linkage between variables in higher levels and lower levels [36]. Consequently, it is reasonable to assume that neighbor support (E6) and accessibility to facilities (E12) have multiple mediation effects between facilities related to physical exercise \& recreation (E10) and the overall QoL of community-dwelling older adults (Q1), and accessibility to facilities (E12) is also the mediator between neighbor support (E6) and Q1.

Hypothesis 2: Natural environment $\rightarrow$ sidewalk condition $\rightarrow$ psychological health.

Hypothesis 3: Natural environment $\rightarrow$ neighbor support $\rightarrow$ psychological health.

Two hypotheses of the dimension of psychological health (Q3) are developed. The psychological health of community-dwelling is mainly influenced by four variables, facilities related daily life (E11), neighbor support (E6), sidewalk condition (E4) and natural environment (E5). According to Figure 4, facilities related daily life (E11) do not have direct relations with the other three variables. Natural 
environment (E5) which is located in level 4 can affect sidewalk condition (E4) and neighbor support (E6) in the level 3 , since natural environment provides a basic environment for community-dwelling older adults' walking and communication outdoors. Therefore, hypothesis 2 assumes sidewalk condition (E4) plays a role of simple mediator in the influence of the natural environment (E5) and Q3, and hypothesis 3 assumes neighbor support (E6) as the simple mediators between natural environment (E5) and Q3.

Hypothesis 4: Neighbor support $\rightarrow$ design-related safety $\rightarrow$ social relationship.

The last hypothesis is related to the dimension of social relationship of older adults (Q4). There are three variables of neighborhood environment, neighbor support (E6), accessibility to facilities (E11) and design-related safety (E15), influencing the social relationship of community-dwelling older adults. In Figure 4, no direct relation exists between accessibility to facilities (E11) and neighbor support (E6) \& design-related safety (E15). However, injuries of older adults can be reduced if older adults are in company with their neighbors, it is possible that neighbor support (E6) can help to enhance design-related safety (E15) [36]. So, it can be assumed that design-related safety (E15) has simple mediation effect in the influence path of neighbor support (E6) on Q4.

\subsection{Results of Mediation Effect Test}

In order to conduct the mediation effect test, the score of each variable of the neighborhood environment and each dimension of QoL is standardized at first. Then, mediation effect tests of four hypotheses are conducted one by one in the PROCESS Procedure. Results of mediation effect tests are shown in Tables 7-10.

Table 7 shows results of the multiple mediation effect test of hypothesis 1 . Coefficients and $F$ value of Models 1-4 in multiple mediation effect test are significant. The $\mathrm{R}^{2}$ of Model 4 is 0.462 , meaning hypothesis 1 can explain $46.2 \%$ of the variance of the overall QoL of community-dwelling older adults. Then, three types of mediation effects are tested by 5000 times' Bootstrap. According to results of 5000 times' Bootstrap, under a confidence level of $95 \%$, the confidence interval of simple mediation effect of the neighbor support is $(0.106,0.285)$; the confidence interval of simple mediation effect of the accessibility to facilities is $(0.056,0.228)$; and the confidence interval of multiple mediation effect is $(0.018,0.095)$. All confidence intervals do not contain 0 , so hypothesis 1 is supported. The neighbor support and the accessibility to facilities do have multiple mediation effects when facilities related to physical exercise \& recreation influences the overall QoL of community-dwelling older adults.

Table 7. Results of the multiple mediation effect test of $\mathrm{H} 1$.

\begin{tabular}{|c|c|c|c|c|c|c|c|c|}
\hline Model & \multicolumn{2}{|c|}{ Model 1} & \multicolumn{2}{|c|}{ Model 2} & \multicolumn{2}{|c|}{ Model 3} & \multicolumn{2}{|c|}{ Model 4} \\
\hline Independent Variable & \multicolumn{2}{|c|}{$\mathrm{Y}=\mathrm{Q1}$} & \multicolumn{2}{|c|}{ M1 = E6 } & \multicolumn{2}{|c|}{$\mathrm{M} 2=\mathrm{E} 12$} & \multicolumn{2}{|c|}{$\mathrm{Y}=\mathrm{Q1}$} \\
\hline & B & S.E. & B & S.E. & B & S.E. & B & S.E. \\
\hline$X=\mathrm{E} 10$ & $0.524^{* * *}$ & 0.062 & $0.507^{* * *}$ & 0.063 & $0.506^{* * *}$ & 0.054 & $0.157^{* *}$ & 0.075 \\
\hline $\mathrm{M} 1=\mathrm{E} 6$ & - & - & - & - & $0.376^{* * *}$ & 0.054 & $0.365^{* * *}$ & 0.070 \\
\hline $\mathrm{M} 2=\mathrm{E} 12$ & & & - & - & - & - & $0.261^{* * *}$ & 0.084 \\
\hline $\mathrm{F}$ & \multicolumn{2}{|c|}{$71.899 * * *$} & \multicolumn{2}{|c|}{$65.882 * * *$} & \multicolumn{2}{|c|}{$136.182^{* * *}$} & \multicolumn{2}{|c|}{$53.743^{* * *}$} \\
\hline $\mathrm{R}$ & \multicolumn{2}{|c|}{0.524} & \multicolumn{2}{|c|}{0.508} & \multicolumn{2}{|c|}{0.768} & \multicolumn{2}{|c|}{0.680} \\
\hline $\mathrm{R}^{2}$ & \multicolumn{2}{|c|}{0.275} & \multicolumn{2}{|c|}{0.258} & \multicolumn{2}{|c|}{0.590} & \multicolumn{2}{|c|}{0.462} \\
\hline \multirow{4}{*}{ Bootstrap } & \multicolumn{2}{|c|}{ Mediation effect } & \multicolumn{2}{|c|}{ Indirect effect } & \multicolumn{2}{|c|}{ BootLLCI } & \multicolumn{2}{|c|}{ BootULCI } \\
\hline & \multirow{2}{*}{\multicolumn{2}{|c|}{$\begin{array}{c}\mathrm{X} \rightarrow \mathrm{M} 1 \rightarrow \mathrm{Y} \\
\mathrm{X} \rightarrow \mathrm{M} 1 \rightarrow \mathrm{M} 2 \rightarrow \mathrm{Y}\end{array}$}} & \multicolumn{2}{|c|}{0.185} & \multicolumn{2}{|c|}{0.106} & \multicolumn{2}{|c|}{0.285} \\
\hline & & & \multicolumn{2}{|c|}{0.045} & \multicolumn{2}{|c|}{0.018} & \multicolumn{2}{|c|}{0.095} \\
\hline & \multicolumn{2}{|c|}{$\mathrm{X} \rightarrow \mathrm{M} 2 \rightarrow \mathrm{Y}$} & \multicolumn{2}{|c|}{0.132} & \multicolumn{2}{|c|}{0.056} & \multicolumn{2}{|c|}{0.228} \\
\hline Hypothesis 1 & \multicolumn{8}{|c|}{ Supported } \\
\hline
\end{tabular}

Note: $\mathrm{B}=$ unstandardized beta; S.E. $=$ standard error; ${ }^{* * *}$-significant at the 0.01 level (2-tailed); ${ }^{* *}$-significant at 0.05 level (2-tailed). 
Table 8 presents results of the mediation effect test of hypothesis 2 . All coefficients and $\mathrm{F}$ value of Model 1-3 in hypothesis 2 is significant. The $\mathrm{R}^{2}$ of Model 3 is 0.118 , so the mediation effect can explain $11.8 \%$ of the variance of psychological health of community-dwelling older adults. And the z-score of Sobel test is significant at 0.05 level. At last, results of 5000 times' Bootstrap present the confidence interval of the mediation effect of the sidewalk condition is $(-0.261,-0.005)$ under a confidence level of $95 \%$. Hypothesis 2 is supported, meaning that the sidewalk condition is a mediator between natural environment and psychological health of community-dwelling older adults.

Table 8. Results of the mediation effect test of $\mathrm{H} 2$.

\begin{tabular}{|c|c|c|c|c|c|c|}
\hline \multirow[t]{2}{*}{$\begin{array}{c}\text { Model } \\
\text { Independent Variable }\end{array}$} & \multicolumn{2}{|c|}{$\begin{array}{c}\text { Model } 1 \\
Y=Q 3\end{array}$} & \multicolumn{2}{|c|}{$\begin{array}{l}\text { Model } 2 \\
M=\mathrm{E} 4\end{array}$} & \multicolumn{2}{|c|}{$\begin{array}{c}\text { Model } 3 \\
Y=Q 3\end{array}$} \\
\hline & B & SE & B & SE & B & SE \\
\hline $\mathrm{X}=\mathrm{E} 5$ & $0.318^{* * *}$ & 0.069 & $-0.705^{* * *}$ & 0.052 & $0.450 * *$ & 0.096 \\
\hline $\mathrm{M}=\mathrm{E} 4$ & - & - & - & - & $0.192 * *$ & 0.096 \\
\hline $\mathrm{F}$ & \multicolumn{2}{|c|}{$20.892 * * *$} & \multicolumn{2}{|c|}{$187.656^{* * *}$} & \multicolumn{2}{|c|}{$12.585^{* * *}$} \\
\hline $\mathrm{R}$ & \multicolumn{2}{|c|}{0.315} & \multicolumn{2}{|c|}{0.705} & \multicolumn{2}{|c|}{0.344} \\
\hline $\mathrm{R}^{2}$ & \multicolumn{2}{|c|}{0.099} & \multicolumn{2}{|c|}{0.497} & \multicolumn{2}{|c|}{0.118} \\
\hline Sobel test & \multicolumn{6}{|c|}{ Indirect effect $=-0.135, \mathrm{Z}=-1.963 * *$} \\
\hline Bootstrap & \multicolumn{2}{|c|}{$\begin{array}{l}\text { Indirect effect } \\
\quad-0.135\end{array}$} & \multicolumn{2}{|c|}{$\begin{array}{c}\text { BootLLCI } \\
-0.261\end{array}$} & \multicolumn{2}{|c|}{$\begin{array}{c}\text { BootULCI } \\
-0.005\end{array}$} \\
\hline
\end{tabular}

Note: $\mathrm{B}=$ unstandardized beta; S.E. $=$ standard error; ${ }^{* * *}$-significant at the 0.01 level (2-tailed); ${ }^{* *}$-significant at 0.05 level (2-tailed)

Results of the mediation effect test of hypothesis 3 are presented in Table 9. Coefficients and $\mathrm{F}$ value of Models $1-3$ are all significant. The $\mathrm{R}^{2}$ of Model 3 is 0.141 , so the natural environment, as the independent variable and the neighbor support as the mediator can explain $14.1 \%$ of the variance of psychological health of community-dwelling older adults. And the z-score of Sobel test is also significant under a confidence level of $95 \%$. At last, the Bootstrap of mediation effect shows that the confidence interval of the mediation effect of the neighbor support is $(0.046,0.244)$ under a confidence level of $95 \%$. Result of Models 1-3, Sobel test and Bootstrap support hypothesis 3. The neighbor support is a mediator in the influence of natural environment on psychological health of community-dwelling older adults.

Table 9. Results of the mediation effect test of $\mathrm{H} 3$.

\begin{tabular}{|c|c|c|c|c|c|c|}
\hline Model & \multicolumn{2}{|c|}{ Model 1} & \multicolumn{2}{|c|}{ Model 2} & \multicolumn{2}{|c|}{ Model 3} \\
\hline Independent Variable & \multicolumn{2}{|c|}{$\mathrm{Y}=\mathrm{Q} 3$} & \multicolumn{2}{|c|}{$\mathrm{M}=\mathrm{E} 6$} & \multicolumn{2}{|c|}{$\mathrm{Y}=\mathrm{Q} 3$} \\
\hline & B & SE & B & SE & B & SE \\
\hline $\mathrm{X}=\mathrm{E} 5$ & $0.315^{* * *}$ & 0.069 & $0.554^{* * *}$ & 0.060 & $0.179 * *$ & 0.081 \\
\hline $\mathrm{M}=\mathrm{E} 6$ & - & - & - & - & $0.246^{* * *}$ & 0.081 \\
\hline $\mathrm{F}$ & \multicolumn{2}{|c|}{$20.892 * * *$} & \multicolumn{2}{|c|}{$84.089^{* * *}$} & \multicolumn{2}{|c|}{$15.500^{* *}$} \\
\hline $\mathrm{R}$ & \multicolumn{2}{|c|}{0.315} & \multicolumn{2}{|c|}{0.554} & \multicolumn{2}{|c|}{0.375} \\
\hline $\mathrm{R}^{2}$ & \multicolumn{2}{|c|}{0.099} & \multicolumn{2}{|c|}{0.307} & \multicolumn{2}{|c|}{0.141} \\
\hline Sobel test & \multicolumn{6}{|c|}{ Indirect effect $=0.136, \mathrm{Z}=2.865^{* * *}$} \\
\hline Bootstrap & \multirow{2}{*}{\multicolumn{2}{|c|}{$\begin{array}{c}\text { Indirect effect } \\
0.136\end{array}$}} & $\begin{array}{r}\text { BootL } \\
0.0\end{array}$ & & \multirow{2}{*}{\multicolumn{2}{|c|}{$\begin{array}{c}\text { BootULCI } \\
0.244\end{array}$}} \\
\hline Hypothesis 3 & & & Supp & & & \\
\hline
\end{tabular}

Note: $\mathrm{B}=$ unstandardized beta; S.E. $=$ standard error; ${ }^{* * *}$-significant at the 0.01 level (2-tailed); ${ }^{* *}$-significant at 0.05 level (2-tailed); ${ }^{*}$-significant at 0.1 level (2-tailed).

Table 10 presents results of the mediation effect test of hypothesis 4 . It exists that not all coefficients and $\mathrm{F}$ value is significant, such as the coefficients of Model 3 is non-significant. And the z-score of Sobel test is also not significant. At last, the Bootstrap of mediation effect shows that the confidence 
interval of the mediation effect of the design-related safety is $(-0.127,0.089)$ under a confidence level of $95 \%$. Since the confidence interval contains 0 , the mediation effect of design-related safety is not supported by data analysis.

Table 10. Results of the mediation effect test of $\mathrm{H} 4$.

\begin{tabular}{|c|c|c|c|c|c|c|}
\hline Model & \multicolumn{2}{|c|}{ Model 1} & \multicolumn{2}{|c|}{ Model 2} & \multicolumn{2}{|c|}{ Model 3} \\
\hline Independent Variable & \multicolumn{2}{|c|}{$\mathrm{Y}=\mathrm{Q} 4$} & \multicolumn{2}{|c|}{$\mathrm{M}=\mathrm{E} 15$} & \multicolumn{2}{|c|}{$\mathrm{Y}=\mathrm{Q} 4$} \\
\hline & B & SE & B & SE & B & SE \\
\hline$X=E 6$ & $0.499^{* * *}$ & 0.063 & $-0.592 * * *$ & 0.059 & $0.510 * * *$ & 0.078 \\
\hline $\mathrm{M}=\mathrm{E} 15$ & - & - & - & - & 0.020 & 0.078 \\
\hline F & \multicolumn{2}{|c|}{$62.892 * * *$} & \multicolumn{2}{|c|}{$102.628^{* * *}$} & \multicolumn{2}{|c|}{$31.323 * * *$} \\
\hline $\mathrm{R}$ & \multicolumn{2}{|c|}{0.499} & \multicolumn{2}{|c|}{0.592} & \multicolumn{2}{|c|}{0.499} \\
\hline $\mathrm{R}^{2}$ & \multicolumn{2}{|c|}{0.249} & \multicolumn{2}{|c|}{0.351} & \multicolumn{2}{|c|}{0.249} \\
\hline Sobel test & \multicolumn{6}{|c|}{ Indirect effect $=-0.012, \mathrm{Z}=-0.251$} \\
\hline Bootstrap & \multirow{2}{*}{\multicolumn{2}{|c|}{$\begin{array}{l}\text { Indirect effect } \\
\quad-0.012\end{array}$}} & \multicolumn{2}{|c|}{$\begin{array}{c}\text { BootLLCI } \\
-0.127\end{array}$} & \multirow{2}{*}{\multicolumn{2}{|c|}{$\begin{array}{c}\text { BootULCI } \\
0.089\end{array}$}} \\
\hline Hypothesis 4 & & & Not sup & orted & & \\
\hline
\end{tabular}

Note: $\mathrm{B}=$ unstandardized beta; S.E. $=$ standard error; ${ }^{* * *}$-significant at the 0.01 level $\left(2\right.$-tailed); ${ }^{* *}$-significant at 0.05 level (2-tailed); ${ }^{*}$-significant at 0.1 level (2-tailed).

Based on the results of this study, the mediation model of neighborhood environment and QoL of community-dwelling older adults which is called the "NE-QoL" the model can be concluded as shown in Figure 5.

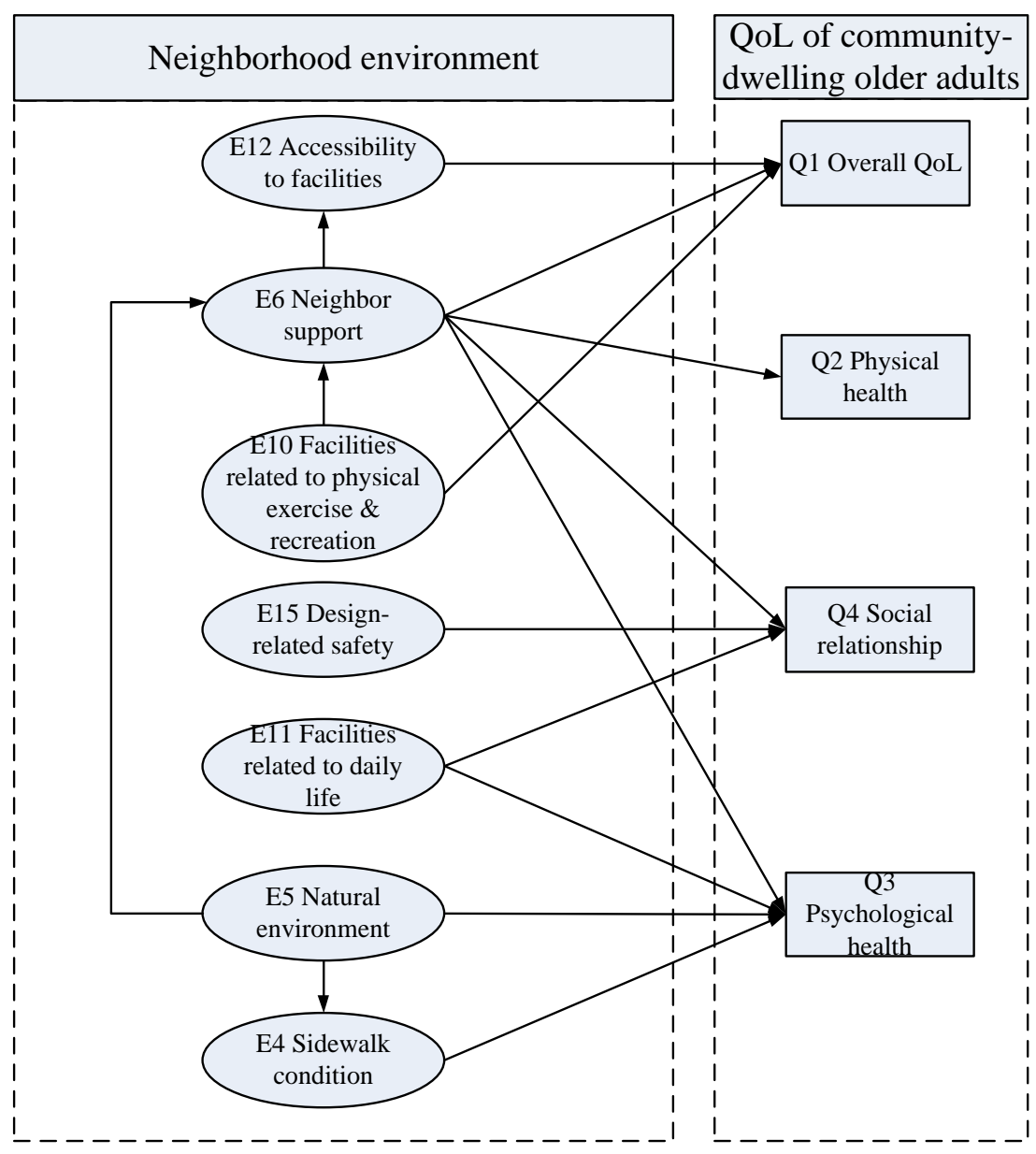

Figure 5. The "NE-QoL" model of community-dwelling older adults. 


\section{Discussion}

It is obvious that urban neighborhood environment does have significant direct and mediation effects on the QoL of community-dwelling older adults according to the results of multiple regression analysis and the mediation effect test. However, influence paths between various variables of neighborhood environment and different dimensions of the QoL are quite different as shown in Figure 5. Detailed influence paths are discussed by dimensions of QoL.

\subsection{Effects of the Neighborhood Environment on the Overall QoL}

The overall QoL of community-dwelling older adults refers to their overall perception of their life, which is measured by their perception of QoL and personal wellbeing [11]. Three variables of neighborhood environment, including the neighbor support, facilities related to physical exercise \& recreation and accessibilities to facilities, have important influences on the overall QoL of communitydwelling older adults. However, these three variables do not work independently, the neighbor support and the accessibility to facilities are multiple mediators which are influenced by facilities related to physical exercise \& recreation, and then influence the overall QoL of community-dwelling older adults. Facilities related to physical exercise \& recreation are places where older adults can do physical exercises or recreate, such as senior centers, fitness equipment, swimming pools, libraries, etc. These facilities provide good opportunities for community-dwelling older adults to exercise, relax, have fun, and then enjoy their lives, increasing their feeling of QoL and personal wellbeing [48].

Besides the direct influence of facilities related to physical exercise \& recreation, there are also mediation effects of the neighbor support in the influence path of facilities related to physical exercise \& recreation on the overall QoL of community-dwelling older adults. Generally, there are two types of neighbor support, one is the formal support which refers to the organized help and communication with neighbors, and the other one is the informal support which means the unscheduled help or communication within the neighborhood [9]. Since facilities related to physical exercise \& recreation are suitable places where neighbors often encounter and communicate with each other, better facilities can encourage community-dwelling older adults to get more familiar with their neighbors and enhance their neighbor support. And the more neighbor support can help community-dwelling older adults feel the daily life is easier and more interesting, then improve their overall perception of their life.

The other mediator is accessibility to facilities. The accessibility to facilities is usually depended on locations of facilities and distance to facilities [46], thus locations and scales of facilities related to physical exercise \& recreation would decide the accessibilities partially. Besides, the traffic condition, road condition and other elements within neighborhood environment also affect the accessibility, since older adults prefer walking to access these facilities [49]. Therefore, when older adults feel difficult to walk or fall down, supports from neighbors can help them to walk to facilities more quickly and safely. And the better accessibility to facilities helps older adults to obtain services and necessities more convenience, and reduce difficulties in their daily life, and then improve the stratification of older adults with their overall QoL.

\subsection{Effects of the Neighborhood Environment on the Physical Health}

The physical health of older adults means the individuals' perception of their physical state [11]. Physical health of older adults is measured by their satisfaction with energy and fatigue, sleep and rest, mobility, activity of daily life, and work capacity. More neighbor supports can help to facilitate mobility and activity of daily life of older adults, and prevent them from physical injuries or sudden diseases. Since only one variable of the neighborhood environment affects the physical health of older adults significantly, no mediation effect exists in this influence path. 


\subsection{Effects of the Neighborhood Environment on the Psychological Health}

The dimension of psychological health refers to older adults' perception of their cognitive and affective state [11]. Their psychological health is assessed by their satisfaction with positive feelings, thinking \& learning \& memory \& concentration, self-esteem, body image and appearance, and negative feelings. Natural environment, sidewalk condition, neighbor support and facilities related to daily life are main variables of neighborhood environment which affect the psychological health of older adults heavily, and two simple mediation effects work in the influence path between natural environment and psychological health. The natural environment generally contains air quality, community afforesting and environment on rainy and snowy days. A better natural environment is a better opportunity for outdoor activities. It makes older adults would like to take a walk within the neighborhood to enjoy their lives, and then improve their positive feelings and other psychological health of older adults.

The sidewalk condition plays the role of mediator between natural environment and psychological health of older adults. The natural environment has closed relationship with the sidewalk condition, because the sidewalk is usually outdoors, exposed in the natural environment. Currently, many communities still cannot realize the "pedestrian-and-vehicle dividing system", so it is unsafe to walk on the road. In addition, older adults prefer to walk rather than cycle or drive within neighborhood, thus, as one of the most important walkable transportation infrastructures, the sidewalk is an infrastructure which older adults heavily rely on. The sidewalk condition, like surface evenness, width and blind sidewalk, can decide a sense of control of older adults [27], and then influence their psychology.

The neighbor support is the other mediator in the influence path of natural environment on psychological health of older adults. As mentioned above, supports from neighbors can be divided into formal and informal supports. No matter the formal support like the team of running and square dancing, or the informal support like encounters and incidental helps, the neighbor support is influenced by natural environment heavily. Since many neighbors supports usually occur outdoors, a good natural environment can increase the quality of the neighbor support. For instance, public spaces with a good air quality and greening are regarded as comfortable places to stay and relax, then square dancing or other neighbor supports on these public spaces will increasing markedly. Meanwhile, both formal and informal neighbor supports can provide opportunities for older adults to communicate with neighbors and get supports of daily life. More communication and supports can release mental pressure of older adults during daily life, bring more enjoyment, and also exercise their abilities of thinking, memory or concentration. Therefore, the natural environment can affect psychological health of older adults through neighbor support.

\subsection{Effects of the Neighborhood Environment on the Social Relationship}

The social relationship of older adults is their perception of interpersonal relationships and social roles in their life [11]. The dimension of social relationship is reflected by older adults' personal relationship and social support. The mediation effect test shows no mediation effect exists between neighbor support and social relationship of older adults, it means that the neighbor support and the design-related safety affect the elderly's social relationship respectively.

The neighbor is originally one important part of social relationship of older adults, so it is obvious that the neighbor support can enhance the social relationship of older adults. And the design-related safety makes older adults feel safe when they stay and wander in facilities or public spaces within the neighborhood. With a safe design of the neighborhood environment, they would like to spend more time on activities in these places, such as exercise and entertainment in facilities, chatting in public spaces. All these activities can enhance their social relationships with other people. 


\section{Conclusions and Implications}

\subsection{Conceptual Implications}

This study develops an influence model of "NE-QoL" for community-dwelling older adults by conducting the multiple regression analysis and the mediation effect test. This "NE-QoL" model reveals the complex influence relations between urban neighborhood environment and the QoL of community-dwelling older adults.

This study focuses on dimensions of QoL of a particular group, community-dwelling older adults. Seven variables of neighborhood environment which significantly affect the QoL of community-dwelling older adults are identified, including sidewalk condition, natural environment, neighbor support, facilities related to physical exercise \& recreation, facilities related to daily life, accessibility to facilities and design-related safety. It indicates that the above variables of neighborhood environment are indeed important influencing factors of QoL of community-dwelling older adults, while other variables of neighborhood environment cannot influence them dramatically. Furthermore, by testing the hypotheses of mediation effects, the neighbor support and accessibility to facilities are identified to have multiple mediation effects when facilities related to physical exercise \& recreation affect the overall QoL of older adults, and the neighbor support and sidewalk condition are two simple mediators in the influence of natural environment on the psychological health of older adults. That means specific variables of neighborhood environment not only influence the QoL of community-dwelling older adults directly, but also influence them through other variables of neighborhood environment which are regarded as mediators.

Consequently, this study uncovers the underlying mechanism between urban neighborhood environment and the QoL of community-dwelling older adults, analyzes the mediation effects in these considerable influence relations, and then develop the "NE-QoL" model of community-dwelling older adults.

\subsection{Practical Implications}

This study can provide valuable practical implications when retrofit strategies of neighborhood environment are made. The QoL of community-dwelling older adults can be improved markedly through neighborhood environment retrofits, finally supporting most of community-dwelling older adults can age in place successfully.

All variables of neighborhood environment appearing in the "NE-QoL" model should be taken into consideration at first, since these variables have more significant direct influence on QoL than other variables of neighborhood environment, and it will be more efficient to retrofit these variables for improving QoL of community-dwelling older adults.

Moreover, among variables in the "NE-QoL" model, three mediators of neighborhood environment should be paid more close attention to when retrofit strategies are made, in order to increase the efficiency of QoL improvement. For instance, accessibility to facilities is a multiple mediator through which facilities related to physical exercise \& recreation impact the overall QoL of community-dwelling older adults, enhancing the accessibility to facilities can help to further increase effects of retrofits of facilities related to physical exercise \& recreation on the overall QoL. The neighbor support is a mediator in several influence paths. So, its retrofits are pretty crucial to improve the efficiency of retrofits of facilities related to physical exercise \& recreation and natural environment. Retrofits of sidewalk condition are also helpful to strengthen effects of natural environment on psychological health of community-dwelling older adults.

\subsection{Limitations and Future Research}

Even though the "NE-QoL" model of community-dwelling older adults are established, providing valuable ideas of retrofit strategies of urban neighborhood environment, some limitations still exist. Since the study area is the urban area of Nanjing, which is a typical large city in China, this study has 
certain representativeness within eastern regions. However, the "NE-QoL" model may change due to regional differences. For instance, the effects of neighbor support may be various under diverse cultures of different regions. In future researches, regional factors will be taken into consideration, and "NE-QoL" models of different regions will be compared and analyzed.

In addition, only the mediation effects of variables of the neighborhood environment are considered in this study. But variables from other aspects may also be mediators between environment and QoL of community-dwelling older adults, such as personal behavior and physical activities. Our future researches will also try to discuss additional mediators from other aspects for the "NE-QoL" model of community-dwelling older adults.

Ethics approval and consent to participate: All procedures performed in this study involving human participation were with ethics approval from an independent research ethics committee of Southeast University. All the participants were informed about the purpose of the study and their right to refuse participation or terminate their involvement during the study and informed consent were obtained.

Author Contributions: Conceptualization, F.Z. and D.L.; methodology, F.Z. and D.L.; software, F.Z.; validation, F.Z. and D.L.; formal analysis, F.Z.; investigation, F.Z.; resources, F.Z. and D.L.; data curation, F.Z. and D.L.; writing—original draft preparation, F.Z.; writing—review and editing, F.Z. and D.L.; visualization, F.Z.; supervision, D.L.; project administration, D.L.; funding acquisition, D.L. and F.Z.

Funding: This research was funded by the National Key Research and Development Program, grant number 2018YFD1100202-05; the MOE (Ministry of Education in China) Project of Humanities and Social Sciences, grant number 17YJAZH038; the Fundamental Research Funds for the Central Universities, grant number 2242019K40063; the Social Science Project of Jiangsu Province, grant number 18GLB002 and Foundation of Outstanding Doctoral Dissertation and Innovative Talents from School of Civil Engineering, Southeast University, grant number CE02-1/2-15.

Acknowledgments: Thanks to Southeast University which provide good opportunity to study and research. And thanks to all the researchers and specialists who have proposed useful advice to this study. Also, thanks to all respondents who have participated in the survey of this study.

Conflicts of Interest: The authors declare no conflict of interest.

\section{References}

1. United Nations. World Population Ageing 2015; Department of Economic and Social Affairs of United Nations: New York, NY, USA, 2015.

2. Chen, L.; Han, W.J. Shanghai: Front-Runner of Community-Based Eldercare in China. J. Aging Soc. Policy 2016, 28, 292-307. [CrossRef] [PubMed]

3. Li, H.; Xu, L.; Chi, I. Perceived Need for Home- and Community-Based Services: Experiences of Urban Chinese Older Adults With Functional Impairments. J. Aging Soc. Policy 2016. [CrossRef] [PubMed]

4. Golant Stephen, M. Residential normalcy and the aging in place behaviors of older Americans. Prog. Geogr. 2015, 34, 1535-1557.

5. Golant, S.M. Aging in the Right Place; Health Preofession Press: Baltimore, MD, USA, 2015.

6. Clarke, P.; Nieuwenhuijsen, E.R. Environments for healthy ageing: A critical review. Maturitas 2009, 64, 14-19. [CrossRef]

7. Loo, B.P.Y.; Mahendran, R.; Katagiri, K.; Lam, W.W.Y. Walking, neighbourhood environment and quality of life among older people. Curr. Opin. Environ. Sustain. 2017, 25, 8-13. [CrossRef]

8. Loo, B.P.; Lam, W.W.; Mahendran, R.; Katagiri, K. How Is the Neighborhood Environment Related to the Health of Seniors Living in Hong Kong, Singapore, and Tokyo? Some Insights for Promoting Aging in Place. Ann. Am. Assoc. Geogr. 2017, 107, 812-828. [CrossRef]

9. Chaudhury, H.; Mahmood, A.; Michael, Y.L.; Campo, M.; Hay, K. The influence of neighborhood residential density, physical and social environments on older adults' physical activity: An exploratory study in two metropolitan areas. J. Aging Stud. 2012, 26, 35-43. [CrossRef]

10. Guyatt, G.H.; Feeny, D.H.; Patrick, D.L. Measuring Health-Related Quality-of-Life. Ann. Intern. Med. 1993, 118, 622-629. [CrossRef]

11. Group, W. The World Health Organization quality of life assessment (WHOQOL): Position paper from the World Health Organization. Soc. Sci. Med. 1995, 41, 1403-1409. [CrossRef] 
12. World Health Organization. WHOQOL_BREF: Introduction, Administration, Scoring and Generic Version of the Assessment (Field Trial Version); World Health Organization: Geneva, Switzerland, 1996.

13. Engel, L.; Chudyk, A.M.; Ashe, M.C.; McKay, H.A.; Whitehurst, D.G.T.; Bryan, S. Older adults' quality of life-Exploring the role of the built environment and social cohesion in community-dwelling seniors on low income. Soc. Sci. Med. 2016, 164, 1-11. [CrossRef]

14. Zhang, Z.; Zhang, J. Perceived residential environment of neighborhood and subjective well-being among the elderly in China: A mediating role of sense of community. J. Environ. Psychol. 2017, 51, 82-94. [CrossRef]

15. Yan, B.Q.; Gao, X.L.; Lyon, M. Modeling satisfaction amongst the elderl, in different Chinese urban neighborhoods. Soc. Sci. Med. 2014, 118, 127-134. [CrossRef] [PubMed]

16. Fernández-Carro, C.; Módenes, J.A.; Spijker, J. Living conditions as predictor of elderly residential satisfaction. A cross-European view by poverty status. Eur. J. Ageing 2015, 12, 187-202. [CrossRef]

17. Wu, J.-H.; Li, S.-H.; Sung, W.-Y. The study of perceived environment and its relation to senior citizen's physical activity behavior intention. J. Bus. Res. 2016, 69, 2259-2264. [CrossRef]

18. Chaudhury, H.; Campo, M.; Michael, Y.; Mahmood, A. Neighbourhood environment and physical activity in older adults. Soc. Sci. Med. 2016, 149, 104-113. [CrossRef]

19. Mooney, S.J.; Joshi, S.; Cerda, M.; Kennedy, G.J.; Beard, J.R.; Rundle, A.G. Contextual Correlates of Physical Activity among Older Adults: A Neighborhood Environment-Wide Association Study (NE-WAS). Cancer Epidemiol. Biomark. Prev. Publ. Am. Assoc. Cancer Res. Cospons. Am. Soc. Prev. Oncol. 2017, 26, 495-504. [CrossRef]

20. Lawton, M.P.; Simon, B. Ecology of Social Relationships in Housing for Elderly. Gerontologist 1968, 8, 108-115. [CrossRef]

21. Lawton, M.P. An Ecological Theory of Aging Applied to Elderly Housing. J. Archit. Educ. 1977, 31, 8-10. [CrossRef]

22. Xie, L.L. Age-Friendly Communities and Life Satisfaction Among the Elderly in Urban China. Res. Aging 2018, 40, 883-905. [CrossRef]

23. Leung, M.-Y.; Famakin, I.; Kwok, T. Relationships between indoor facilities management components and elderly people's quality of life: A study of private domestic buildings. Habitat Int. 2017, 66, 13-23. [CrossRef]

24. Friedman, D.; Parikh, N.S.; Giunta, N.; Fahs, M.C.; Gallo, W.T. The influence of neighborhood factors on the quality of life of older adults attending New York City senior centers: Results from the Health Indicators Project. Qual. Life Res. Int. J. Qual. Life Asp. Treat. Care Rehabil. 2012, 21, 123-131. [CrossRef] [PubMed]

25. Levasseur, M.; Desrosiers, J.; Noreau, L. Relationships between environment and quality of life of older adults with physical disabilities. Phys. Occup. Ther. Geriatr. 2004, 22, 37-53. [CrossRef]

26. Yu, J.Y.; Ma, G.X.; Jiang, X.Y. Impact of the built environment and care services within rural nursing homes in China on quality of life for elderly residents. Eng. Constr. Archit. Manag. 2017, 24, 1170-1183. [CrossRef]

27. Koehn, S.D.; Mahmood, A.N.; Stott-Eveneshen, S. Quality of Life for Diverse Older Adults in Assisted Living: The Centrality of Control. J. Gerontol. Soc. Work. 2016, 59, 512-536. [CrossRef]

28. Parra, D.C.; Gomez, L.F.; Sarmiento, O.L.; Buchner, D.; Brownson, R.; Schimd, T.; Gomez, V.; Lobelo, F. Perceived and objective neighborhood environment attributes and health related quality of life among the elderly in Bogota, Colombia. Soc. Sci. Med. 2010, 70, 1070-1076. [CrossRef]

29. Zhao, Y.; Chung, P.K. Neighborhood environment walkability and health-related quality of life among older adults in Hong Kong. Arch. Gerontol. Geriatr. 2017, 73, 182-186. [CrossRef]

30. Vogt, S.; Mielck, A.; Berger, U.; Grill, E.; Peters, A.; Doring, A.; Holle, R.; Strobl, R.; Zimmermann, A.K.; Linkohr, B.; et al. Neighborhood and healthy aging in a German city: Distances to green space and senior service centers and their associations with physical constitution, disability, and health-related quality of life. Eur. J. Ageing 2015, 12, 273-283. [CrossRef]

31. Subramanian, S.V.; Kubzansky, L.; Berkman, L.; Fay, M.; Kawachi, I. Neighborhood effects on the self-rated health of elders: Uncovering the relative importance of structural and service-related neighborhood environments. J. Gerontol. Ser. B Psychol. Sci. Soc. Sci. 2006, 61, S153-S160. [CrossRef]

32. Dujardin, C.; Lorant, V.; Thomas, I. Self-assessed health of elderly people in Brussels: Does the built environment matter? Health Place 2014, 27, 59-67. [CrossRef]

33. Chen, Y.Y.; Wong, G.H.; Lum, T.Y.; Lou, V.W.; Ho, A.H.; Luo, H.; Tong, T.L. Neighborhood support network, perceived proximity to community facilities and depressive symptoms among low socioeconomic status Chinese elders. Aging Ment. Health 2016, 20, 423-431. [CrossRef] 
34. Clarke, P.J.; Weuve, J.; Barnes, L.; Evans, D.A.; Mendes de Leon, C.F. Cognitive decline and the neighborhood environment. Ann. Epidemiol. 2015, 25, 849-854. [CrossRef] [PubMed]

35. Alidoust, S.; Bosman, C.; Holden, G. Talking while walking: An investigation of perceived neighbourhood walkability and its implications for the social life of older people. J. Hous. Built Environ. 2017, 33, 133-150. [CrossRef]

36. Zhang, F.; Li, D.; Ahrentzen, S.; Feng, H. Exploring the inner relationship among neighborhood environmental factors affecting quality of life of older adults based on SLR-ISM method. J. Hous. Built Environ. 2019. [CrossRef]

37. Lawton, M.P.; Windley, P.G.; Byerts, T.O. Aging and the Environment: Theoretical Approaches; Springer Publishing Company: New York, NY, USA, 1982.

38. Zhang, F.; Li, D. How Urban Neighborhood Environment Affects Quality of Life of Older Adults: Enlightenments for Supporting "Aging in Place". In Proceedings of the 2019 International Conference on Construction and Real Estate Management: Construction Enterprises and Project Management (ICCREM 2019), Banff, AB, Canada, 21-24 May 2019.

39. Hair, J.; Black, W.C.; Babin, B.J.; Anderson, R.E. Multivariate Data Analysis: International Version; Pearson Education Limited: Upper Saddle River, NJ, USA, 2010.

40. Kaiser, H.F. The Varimax Criterion for Analytic Rotation in Factor-Analysis. Psychometrika 1958, 23, $187-200$. [CrossRef]

41. Hayes, A.F. Introduction to Mediation, Moderation, and Conditional Process Analysis: A Regression-Based Approach; Guilford Publications: New York, NY, USA, 2017.

42. MacKinnon, D. Introduction to Statistical Mediation Analysis; Lawrence \& Erlbaum Associates: New York, NY, USA, 2008.

43. Hayes, A.F. Beyond Baron and Kenny: Statistical Mediation Analysis in the New Millennium. Commun. Monogr. 2009, 76, 408-420. [CrossRef]

44. Fang, J.; Wen, Z.; Zhang, M.; Sun, P. The Analyses of Multiple Mediation Effects Based on Structural Equation Modeling. J. Psychol. Sci. 2014, 37, 735-741. (In Chinese)

45. Ott, R.L.; Longnecker, M.T. An Introduction to Statistical Methods and Data Analysis, 6th ed.; Cengage Learning: Boston, MA, USA, 2008.

46. Ingram, D.R. The concept of accessibility: A search for an operational form. Reg. Stud. 1971, 5, $101-107$. [CrossRef]

47. Zhang, F.; Li, D.; Ahrentzen, S.; Zhang, J. Assessing spatial disparities of accessibility to community-based service resources for Chinese older adults based on travel behavior: A city-wide study of Nanjing, China. Habitat Int. 2019, 88, 101984. [CrossRef]

48. Ruengtam, P. Factor Analysis of Built Environment Design and Management of Residential Communities for Enhancing the Wellbeing of Elderly People. Procedia Eng. 2017, 180, 966-974. [CrossRef]

49. Feng, J.; Yang, Z. Factors influencing travel behavior of urban elderly people in Nanjing. Prog. Geogr. 2015, 34, 1598-1608. (In Chinese)

(C) 2019 by the authors. Licensee MDPI, Basel, Switzerland. This article is an open access article distributed under the terms and conditions of the Creative Commons Attribution (CC BY) license (http://creativecommons.org/licenses/by/4.0/). 